\title{
Research article \\ Alternations in serum vitamin D, calcium, phosphorus and lipid profile levels in newly diagnosed type 2 diabetic patients of North-West India
}

Kuldip Singh ${ }^{1}$, Asha Khubchandani ${ }^{2}$, Sarbjot Singh $^{3}$

${ }^{1}$ Professor, Department of Biochemistry Government Medical College, Patiala, Punjab, India

${ }^{2}$ Department of Biochemistry, B.J. Medical College, Ahmedabad, Gujarat, India

${ }^{3}$ Senior Resident, Department of Surgery, Government Medical College, Amritsar, Punjab, India

(Received: October $2020 \quad$ Revised: March $2021 \quad$ Accepted: April 2021)

Corresponding author: Kuldip Singh. Email: drkuldip08@gmail.com

\begin{abstract}
Introduction and Aim: Thirty-two million Indians are suffering with diabetes mellitus worldwide and predicted that this number of diabetes to be increased to 80 million by 2030. Many reports revealed a positive relationship between diabetic patients suffering with $25(\mathrm{OH}) \mathrm{D}$ deficiency. In developing nations like India $60 \%$ adults were found showing manifestations of vitamin D deficiency and dyslipidemia, a well-known risk factor for the development of diabetes mellitus. Therefore, we designed the study to evaluate alterations in vitamin $\mathrm{D}$, calcium, and phosphorus along with complete lipid profile levels in newly diagnosed type 2 diabetic patients in North-West Indians.
\end{abstract}

Materials and Methods: One hundred fifty newly diagnosed type 2 diabetic patients and equal number of healthy control subjects of both genders were recruited in the study. $5 \mathrm{ml}$ of blood was collected by venipuncture after 12 14 hours fasting in plain and potassium oxalate: sodium fluoride vial. Serum and plasma were separated and used for the determination of $25(\mathrm{OH}) \mathrm{D}$ levels, calcium, phosphorus and complete lipid profile levels.

Results: A significantly $(\mathrm{p}<0.001)$ high level of glucose was observed in newly diagnosed type 2 diabetics subjects while a significant fall ( $p<0.001$ ) was recorded in vitamin D levels in newly diagnosed type 2 diabetics in comparison to healthy control subjects. The nominal changes were seen in calcium and phosphorus levels in newly diagnosed type 2 diabetics with respect to healthy control subjects. Statistically significant increase was found in total cholesterol $(p<0.05)$, triglyceride $(p<0.001)$ and VLDL-cholesterol $(p<0.001)$ levels while no significant changes was observed in LDL- cholesterol and HDL- cholesterol levels in newly diagnosed type 2 diabetics with respect to healthy subjects.

Conclusion: Aforementioned observations suggested that a significant decrease in vitamin D levels was associated with increased glucose and lipid levels like total cholesterol, triglycerides and VLDL-cholesterol levels could be responsible for the initiation of various diseases like diabetes mellitus, cardiovascular diseases, osteoporosis etc. Hence, new interventions should be included as a part of treatment to reduce the risk of type-2 diabetics and CVDs like atherosclerosis

Keywords: Diabetes mellitus; dyslipidemia; cardiovascular diseases; vitamin-D; lipid profile.

\section{INTRODUCTION}

$\mathrm{T}$ he incidences of Diabetes mellitus (DM), a common chronic and non-communicable disease are increasing at an alarming rate worldwide (1). The literature reports reveal that the incidences diabetes increased to 80 million by 2030 (2). In India, 32 million peoples are suffering with diabetes, currently has the highest incidence of diabetes worldwide and predicted that this number is predicted to increase to 80 million by the year 2030 (3).

There are many reports, which indicated that vitamin D deficiency alters insulin synthesis and secretion in both humans \&animal models may predispose to glucose intolerance and hence cause type 2 diabetes mellitus $(4,5,6)$. The supplementation of vitamin $\mathrm{D}$ improves glycaemia and insulin secretion in diabetic patients suffering with vitamin $\mathrm{D}$ deficiency could be due the presence of vitamin $\mathrm{D}$ receptors and vitamin
D binding protein in pancreatic tissue. Further, this hypothesis is supported by the association of certain allelic variations in the vitamin $\mathrm{D}$ receptors and vitamin $\mathrm{D}$ binding proteins suggesting that vitamin $\mathrm{D}$ play an important role to regulate certain pathways related to type 2 diabetes developments $(6,7)$. Therefore, Deficiency of vitamin D could result in the initiation of chronic diseases like Type 2 diabetes mellitus (DM) and cardiovascular diseases (8).

In India, more about $70 \%$ adults in both rural and urban areas were found showing manifestations of vitamin D deficiency (3, 9). Literature search revealed that the data regarding the status of vitamin $\mathrm{D}$ in adult Indian population is scarcely available. Since, both type 2 diabetes and deficiency of vitamin $\mathrm{D}$ are highly prevalent in Indian population. There is ample evidence that abnormalities in lipid metabolism are important risk factors for increased incidence of diabetes-associated complications. The 
most important risk indicators for these complications are dyslipidemia. Therefore, we designed this study to assess the vitamin D status, serum calcium, serum phosphorus along with complete serum lipid profile like total cholesterol, triglyceride, HDL-cholesterol, LDL-cholesterol and VDRL- cholesterol levels in newly diagnosed diabetic patients.

\section{STUDY DESIGN AND MATERIALS}

A case control cross-sectional prospective study was conducted in Biochemistry Department, GMCPatiala on 150 diabetics (study Group) and 150 healthy subjects (Control Group).

Inclusion and Exclusion criteria: The subjects of both sexes in the age of 18-35 years were recruited from rural and urban area of Punjab in both groups (study Group and Control, Group). Study Group comprised of 150 newly conformed type 2 diabetics patients with more than $140 \mathrm{mg} / \mathrm{dl}$ fasting blood glucose level and suffering with other complications like mellitus polyuria, polydipsia, fatigue, weight loss. In the control group 150 healthy subjects were included while the patients suffering with chronic diseases like diabetes Mellitus (DM), hypertension, hypothyroidism, renal failure, hepatic diseases, acute illnesses, recurrent myocardial infarction, unstable angina, taking vitamin D supplementation and pregnant \& nursing mothers were excluded from the study.

All subjects recruited for the study were vegetarian, non-smokers and non-alcoholic, with no positive family history of diabetes, cardiovascular diseases (CVD).

\section{Ethical Approval:}

The Institution Ethical Committee approval and written consent from the subjects participated in the study was taken prior to initiate the study. The questionnaire such as lifestyle, medical history, diet, height $(\mathrm{cm})$, weight $(\mathrm{kg})$, heart rate, body mass index (BMI) was recorded. The blood pressure 3 times a day in the sitting position along with plasma glucose, complete lipid profile and vit. D levels was determined to assess whether the subjects suffering with any chronic diseases like diabetes, heart failure etc. or to fulfill the requisite criteria of the study or not?

\section{Data collection}

Measurements of anthropometric parameters: The anthropometric parameters like weight and height were noted in kilogram $(\mathrm{kg})$ and centimeters respectively. The BMI was calculated as under from weight and height of the patients

$\mathrm{BMI}=$ weight in $\mathrm{kg} /$ (height in meters) $^{2}$.

Serum and Plasma preparation: $5 \mathrm{ml}$ of blood was collected after overnight fasting from study group and control group subjects. $3 \mathrm{ml}$ of blood was collected in a plain vial \& kept at $37{ }^{\circ} \mathrm{C}$ for 30 minutes and $2 \mathrm{ml}$ of blood was collected in a potassium oxalate and sodium fluoride vial. The plain vial and potassium oxalate \& sodium fluoride vial was centrifuged at $4000 \mathrm{rpm}$ for 10 minutes. Serum and plasma were prepared from plain vial and potassium oxalate \& sodium fluoride vial respectively was used for various biochemical parameters.

\section{Biochemical Assays}

1. Estimation of Fasting plasma glucose levels: The determination of Glucose in plasma of both study group and healthy control subjects was done by GOD-POD method supplied by TransAsia Biomedical Private Limited, Mumbai (India).

2. Estimation of serum calcium: Calcium levels were estimated spectrophotometrically using a standardized test kit supplied by TransAsia Biomedical Private Limited, Mumbai (India).

3. Estimation of serum phosphorus: Phosphorus levels were estimated spectrophotometrically using a standardized test kit supplied by TransAsia Biomedical Private Limited, Mumbai (India).

4. Estimation of serum lipoprotein levels: Lipoprotein levels like T-Cho. TGs, HDL-Cho., were determined by using commercially available kits procured from TransAsia Biomedical Private Limited, Mumbai (India). LDL-Cholesterol was calculated by using the empirical equation of Bates and Warren, 1989 (10). Serum LDL-cholesterol= Total cholesterol - [HDL + Triglyceride/5] and very low-density lipoprotein cholesterol was calculated by dividing triglyceride concentration with 5 .

5. Estimation of vitamin D: Vitamin D was estimated by ELISA method based standardized kit.

\section{Statistical Analysis}

The data was expressed as Mean \pm SD and analyzed with the SPSS 16.0.7 statistical software package. Differences between the study group and control group subjects were by using the student's independent samples t-test was evaluated. Differences were considered statistically significant at $P<0.05$.

\section{RESULTS}

\section{Anthropometric parameters}

The Anthropometric measurements of both obese and normal healthy control subjects are summarized in the table1. The body weight, height, BMI, BP systolic and BP-diastolic was $74.34 \pm 4.95 \mathrm{~kg}, 169.92$ 
$\pm 6.83 \mathrm{~cm}, 25.78 \pm 7.30 \mathrm{Kg} / \mathrm{m}^{2}, 123.71 \pm 3.24 \mathrm{mmHg}$ and $80.81 \pm 3.91 \mathrm{mmHg}$ respectively in type 2 Diabetic patients with respect to $67.68 \pm 5.17 \mathrm{~kg}$,
$168.23 \pm 6.12 \mathrm{~cm}, 23.32 \pm 5.11 \mathrm{Kg} / \mathrm{m}^{2} 83.72 \pm$ $4.32 \mathrm{mmHg}$ and $79.11 \pm 3.89 \mathrm{mmHg}$ respectively of healthy control subjects.

Table 1: Status of study group (Newly diabetic) patients and control group (healthy) subjects

\begin{tabular}{|c|c|c|c|}
\hline Anthropometric assays & $\begin{array}{c}\text { Normal healthy } \\
\text { subjects }(\mathbf{n = 1 5 0})\end{array}$ & $\begin{array}{c}\text { Newly diagnosed type 2 } \\
\text { diabetic patients (n=150) }\end{array}$ & P value \\
\hline Subject Number & 150 & 150 & - \\
\hline Gender (Male / Female) & $86 / 64$ & $88 / 62$ & - \\
\hline Height (cm) & $168.23 \pm 6.12$ & $169.92 \pm 6.83$ & - \\
\hline Weight $(\mathrm{kg})$ & $67.68 \pm 5.17$ & $74.34 \pm 4.95$ & - \\
\hline Age (years) & $30.21 \pm 6.25$ & $29.21 \pm 7.50$ & - \\
\hline Body mass index $\left(\mathrm{Kg} / \mathrm{m}^{2}\right)$ & $23.91 \pm 4.71$ & $25.72 \pm 4.45$ & - \\
\hline Blood pressure systolic $(\mathrm{mmHg})$ & $83.72 \pm 4.32$ & $123.71 \pm 3.24$ & - \\
\hline Blood pressure diastolic $(\mathrm{mmHg})$ & $79.11 \pm 3.89$ & $80.81 \pm 3.91$ & - \\
\hline
\end{tabular}

\section{Glucose, calcium and phosphorus}

The levels of fasting glucose levels, calcium and phosphorus are summarized in table2. The fasting plasma glucose levels in newly diagnosed type 2 diabetic patients and in healthy control subject fasting plasma glucose levels was found84.96 \pm $3.67 \mathrm{mg} / \mathrm{dl}$. A significant $(\mathrm{p}<0.001)$ increase in plasma glucose levels was recorded in newly diagnosed type 2 diabetic patients with respect to healthy control subjects while insignificant changes were seen in serum calcium and serum phosphorus (Table2). The levels of serum calcium and phosphorus was $9.24 \pm 0.40 \mathrm{mg} / \mathrm{dL}$ and $3.76 \pm$ $0.29 \mathrm{mg} / \mathrm{dL}$ respectively in newly diagnosed type 2 diabetic patients and $9.53 \pm 0.42 \mathrm{mg} / \mathrm{dL}$ and $3.93 \pm$ $0.31 \mathrm{mg} / \mathrm{dL}$ in healthy control subjects. No statistical change in serum calcium and phosphorus was found in comparison to healthy control subjects (Table2).

Table 2: Alterations in serum vitamin D, fasting blood glucose, calcium and phosphorus levels in newly diagnosed Type 2 Diabetics patients and healthy control subjects.

\begin{tabular}{|c|c|c|}
\hline Biochemical assays & Normal healthy subjects $(\mathbf{n}=\mathbf{1 5 0})$ & $\begin{array}{c}\text { Newly diagnosed type 2 } \\
\text { diabetic patients }(\mathbf{n}=\mathbf{1 5 0})\end{array}$ \\
\hline Fasting Blood Glucose(mg/dL) & $84.96 \pm 3.67$ & $135.70 \pm 5.38(+59.72)^{* * *}$ \\
\hline Calcium(mg/dL) & $9.53 \pm 0.42$ & $9.24 \pm 0.40(-3.04)^{\mathrm{NS}}$ \\
\hline Phosphorus(mg/dL) & $3.93 \pm 0.31$ & $3.76 \pm 0.29(-4.32)^{\mathrm{NS}}$ \\
\hline Serum Vitamin-D(ng/mL) & $62.86 \pm 9.01$ & $39.12 \pm 8.18(-37.77)^{* * *}$ \\
\hline
\end{tabular}

NS= Not significant $\quad * * *$ Highly significant

\section{Lipid profile levels}

The levels of lipoprotein fractions are summarized in Table-2. The lipid profile such as total cholesterol, triglycerides, LDL-cholesterol, HDL-cholesterol and VLDL-cholesterol levels was $188.76 \pm 41.57 \mathrm{mg} / \mathrm{dL}$, $153.74 \pm 67.71, \mathrm{mg} / \mathrm{dL}, 109.79 \pm 16.05 \mathrm{mg} / \mathrm{dL}, 48.23 \pm$ $12.17 \mathrm{mg} / \mathrm{dL}$ and $30.74 \pm 4.65 \mathrm{mg} / \mathrm{dL}$ in newly diagnosed type 2 diabetic patients in comparison to $167.25 \pm 29.41 \mathrm{mg} / \mathrm{dL}, \quad 109.12 \pm 45.15 \mathrm{mg} / \mathrm{dL}$, $103.85 \pm 15.40 \mathrm{mg} / \mathrm{dL}, 41.58 \pm 11.16 \mathrm{mg} / \mathrm{dL}$ and 21.82 $\pm 9.24 \mathrm{mg} / \mathrm{dL}$ levels of total cholesterol, triglycerides,
LDL-cholesterol, HDL- cholesterol and VLDLcholesterol respectively in normal healthy control subjects. Statistically significant increase was recorded in newly diagnosed type 2 diabetic patients with respect to healthy control subjects in fasting glucose levels, but no statistically significant difference was observed in lipid profile levels in newly diagnosed type 2 diabetic patients with respect to normal healthy subjects and the lipid profile levels were remained within the normal limit. The levels of lipoprotein fractions are summarized in Table3.

Table 3: Alterations in serum total cholesterol, triglyceride, HDL-Cholesterol, LDL-Cholesterol and VDRLCholesterol levels in newly diagnosed Type 2 Diabetics patients and healthy control subjects.

\begin{tabular}{|c|c|c|}
\hline Biochemical Assays & $\begin{array}{c}\text { Normal Healthy Control } \\
\text { Subjects(n=150) }\end{array}$ & $\begin{array}{c}\text { Newly Diagnosed Type 2 } \\
\text { Diabetic Patients(n=150) }\end{array}$ \\
\hline Total Cholesterol(mg/dL) & $167.25 \pm 29.41$ & $188.76 \pm 41.57(+23.03) *$ \\
\hline Triglyceride(mg/dL) & $109.12 \pm 45.15$ & $153.74 \pm 67.71(+40.89)^{* * *}$ \\
\hline LDL-Cholesterol(mg/dL) & $103.85 \pm 15.40$ & $109.79 \pm 16.05(+5.72)^{\text {NS }}$ \\
\hline HDL-Cholesterol(mg/dL) & $41.58 \pm 11.16$ & $48.23 \pm 12.17(+2.50)^{\text {NS }}$ \\
\hline VDRL- Cholesterol(mg/dL) & $21.82 \pm 9.24$ & $30.74 \pm 4.65(+40.87)^{* *}$ \\
\hline
\end{tabular}

\section{Vitamin D}

A significant decrease was recorded in vitamin- $D$ levels (from $62.86 \pm 9.01 \mathrm{ng} / \mathrm{ml}$ to $39.12 \pm 8.18 \mathrm{ng} / \mathrm{ml}$ in newly diagnosed type 2 diabetic patients by $37.77 \%$ ( $\mathrm{p}<0.001)$ with respect to normal healthy subjects (Table 2) 


\section{DISCUSSION}

In the present cross-sectional study, a significant decrease in serum $25(\mathrm{OH})$ D levels $(37.77 \%$; $p$ < 0.001 ) whereas a nominal (insignificant) changes were found in serum calcium and serum phosphorus levels in newly diagnosed type 2 diabetic patients with respect to healthy subjects (Table2). Vitamin D helps in regulating bone health and mineral homeostasis. However, in most of the tissue's vitamin-D receptors are widely distributed and also have many exoskeleton effects.

Recent studies have confirmed that vitamin D is also involved in the metabolic regulation of calcium and phosphorus metabolism, plays an important role in maintaining intracellular and extracellular calcium homeostasis. In addition to its association with bone health, vitamin $\mathrm{D}$ is also associated with insulin resistance, diabetes, obesity, hypertension, atherosclerosis and other diseases (11).A significant increase was observed in total cholesterol $(23.03 \%$; $<0.05)$, triglyceride $(40.89 \%$; $<$ 0.001) and VRDLcholesterol $(40.88 \% ; \mathrm{p}<0.001)$ levels while nominal changes were recorded in the levels of HDLcholesterol (2.50\%), LDL- cholesterol (5.72\%) study group patients with respect to control group subjects (Table 3). The results of our present study showed that vitamin $\mathrm{D}$ was negatively correlated with fasting blood glucose, total cholesterol, triglyceride and after adjusting for gender, age and BMI.

Most of the observational studies have shown that vitamin D was negatively correlated with fasting blood glucose (12-14), total cholesterol, triglycerides, LDL-cholesterol and positively correlated with serum HDL-cholesterol (15-18). In 2017, Ford et al., reported a negative relationship between $25(\mathrm{OH}) \mathrm{D}$ and triglycerides levels in hypotriglyceridemic patients (19). However, this relationship was not observed with regard to HDL cholesterol in healthy subjects. Szternel et al., (14) showed that serum vitamin D level was negatively correlated with fasting blood glucose and total cholesterol in children aged 9-11 years, and every $1 \mathrm{ng} / \mathrm{mL}$ reduction in $25(\mathrm{OH}) \mathrm{D}$ concentration was associated with a 0.013 $\mathrm{mmol} / \mathrm{L}$ increase in fasting blood glucose, a 0.25 $\mathrm{mmol} / \mathrm{L}$ increase in total cholesterol and a 0.015 $\mathrm{mmol} / \mathrm{L}$ decrease in HDL-cholesterol.

It is well established that vitamin-D deficiency causes insulin resistance because vitamin D via its receptor (VDR), present in pancreas and nerve tissue stimulates the production of insulin directly. However, vitamin D deficiency may indirectly affect the variations of calcium level during insulin secretion, signal transduction and the activity of glucose transporter. In addition, insulin secretion is a calcium-dependent process, and vitamin D indirectly regulates the function of cells by regulating extracellular calcium and calcium fluxes $(11,20)$. So, a lack of vitamin D or calcium intake may alter the stability of the intracellular and extracellular calcium pools, which in turn may affect the normal secretion of insulin. Vitamin D can improve lipid metabolism by inhibiting parathyroid hormone secretion, which in turn can reduce fat breakdown and increasing blood calcium level and increased calcium level can reduce the formation and secretion of liver triglyceride (21). Vitamin D supplementation may reduce the rate of conversion from pre-diabetes to diabetes.

\section{CONCLUSION}

Aforementioned observations suggested that reduced $25(\mathrm{OH}) \mathrm{D}$ concentrations associated with increased glucose and lipid levels like total cholesterol, triglycerides and VLDL-cholesterol levels might be responsible for the initiation of etiology of various diseases like diabetes mellitus, atherosclerosis, osteoporosis etc. Therapeutic interventions in combinations, lifestyle and dietary modification might be beneficial to increase the vitamin $\mathrm{D}$ levels and to reduce the lipid levels should be included as a part of treatment in newly diagnosed type-2 diabetics to prevent further risk of development of diabetes mellitus and various cardiovascular diseases in Northwest Indians.

\section{CONFLICT OF INTEREST}

Authors declare no conflict of interest.

\section{REFERENCES}

1. Ahmed, S., Taheri, E., Mahmoud, D., Ali, M. M., Mosttafa, Q. Association between serum level of vitamin $\mathrm{D}$ and lipid profile in type 2 diabetic patients in Iran. J. Diabetes and Metab. Disorders. 2014; 13(7): 1-5.

2. Wild, S., Roglic, G., Green, A., Sicree, A., King, H Global prevalence of diabetes estimates for the year 2000 and projections for 2030. Diabetes Care. 2004; 27(5): 1047-1053.

3. Kumar, B. J. P., Itaggappa, M., Thimmaraju, K. V. Association of vitamin-D deficiency with oxidative stress in newly diagnosed type 2 diabetes. Int. J. Res. Med. Sci. 2017; 5: 5221-5226.

4. Palomer, X., Gonzalez, C. J. M., Blanco, V. F., Mauricio, D. Role of vitamin D in the pathogenesis of type 2 diabetes mellitus. Diabetes ObesMetab. 2008; 10(3): 185-1897.

5. Chagas, C. E. A., Borges, M. C., Martini, L. A., Rogero, M. M. Focus on vitamin D, inflammation and type 2 diabetes. Nutrients. 2012; 4(1): 52-67.

6. Bazhecht, M., Goldfine, A. B. The impact of vitamin D deficiency on diabetes and cardiovascular risk. Curr. Opin. Endocrinol. Diabetes Obes. 2010; 17(2): 113-119.

7. Anjana, R. M., Pradeepa, R., Deepa, M., Datta, M., Sudha, V., Unnikrishnan, R., et al., Prevalence of diabetes and prediabetes (impaired fasting glucose and/or impaired glucose tolerance) in urban and rural India: phase I results of the Indian Council of Medical Research-India Diabetes (ICMR-INDIAB) study. Diabetologia. 2011; 54(12): 3022-3027.

8. Wang, T., Pencina, M., Booth, S., Jacques, P., Ingelsson, E., Lanier, K. et al., Vitamin D deficiency and risk of cardiovascular disease. Circulation. 2008; 117: 503-511.

9. Badyal, A., Kumar, S., Chander, K. Evaluation of vitamin $d$ and oxidative stress status in patients of type-2 
diabetes. Inter. J.Current Adv. Res.2019; 8(4): 1807818080.

10. Bates, C. M., Warren, G. S. Estimation of low-density lipoprotein cholesterol. South Med. J. 1989; 82: 570575.

11. Chinese Association of osteoporosis and bone mineral salt disease. [Consensus on the clinical application of vitamin D and its analogs]. Chin. J. Osteoporosis Bone Miner Res. 2018; 11: 1-13.

12. Yan, X., Thomson, J. S., Zhao, R., Zhu, R., Wang, Z., Zhang, N., Coad, J. Vitamin D Status of Residents in Taiyuan, China and influencing factors. Nutrients. 2017; 9(8): 898- 904.

13. Diaz, G. M., Gonzalez, L., Ramos, T. G., Perez, C. M., Palacios, C. Vitamin D status is associated with metabolic syndrome in a clinic-based sample of hispanic adults. Metab. Syndr. Relat. Disord. 2016; 14(5): 259264.

14. Szternel, L., Krintus, M., Bergmann, K., Derezinski, T., Sypniewska, G. Association between fasting glucose concentration, lipid profile and $25(\mathrm{OH}) \mathrm{D}$ status in children aged 9- 11. Nutrients. 2018; 10(10): 1359-1363.

15. Souza, W. N., Aparicio, U. R., Bibiloni, M. M., Palacios, G., Aguilar, I., Tur, J. A., Gross, M.G. Better body composition and lipid profile can be associated with vitamin D status in Spanish elderly? The PHYSMED study. J. Nutr. Health Aging. 2017; 21(10): 1329-1336.

16. Jiang, X., Peng, M., Chen, S., Wu, S., Zhang, W. Vitamin D deficiency is associated with dyslipidemia: a cross-sectional study in 3,788 subjects. Curr. Med. Res.Opin. 2019; 35(6): 1059-1063.

17. Huang, C. Y., Chang, H. H., Lu, C. W., Tseng, F. Y., Lee, L. T., Huang, K. C. Vitamin D status and risk of metabolic syndrome among non-diabetic young adults. Clin. Nutr. 2015; 34(3): 484-489.

18. Delvin, E. E., Lambert, M., Levy, E., O’Loughlin, J., Mark, S., Gray-Donald, K., Paradis, G. Vitamin D status is modestly associated with glycemia and indicators of lipid metabolism in French-Canadian children and adolescents. J.Nutr. 2010; 140 (5): 987-991

19. Ford, E. S., Ajani, U. A., McGuire, L. C., Liu, S. Concentrations of serum vitamin D and the metabolic syndrome among U.S. adults. Diabetes Care. 2017; 28(5): 1228-1230.

20. Viljakainen, H. T., Vaisanen, M., Kemi, V., Rikkpnen, T., Kroger, H., Laitinen, E. K. A. et al., Wintertime vitamin $\mathrm{D}$ supplementation inhibits seasonal variation of calciotropic hormones and maintains bone turnover in healthy men. J. Bone Miner. Res. 2009; 24(2): 346-352.

21. Nurliyana, N. M. R., Huzwah,N. K. Review on Potential Vitamin D Mechanism with Type 2 Diabetes Mellitus Pathophysiology in Malaysia. Curr. Res.Nutr. Food. Sci. 2018;6(1).doi:http://dx.doi.org/10.12944/CRNFSJ.6.1.0 1 